\title{
The Concept of Intellectual Capital Managementin the Conditions of Digitization of the Economy
}

\author{
Niyaz M. Abdikeev ${ }^{1}$, Olga V. Loseva ${ }^{2}$, \\ Marina V. Melnichuk ${ }^{3}$ \\ Financial University under the Government of the Russian Federation \\ Moscow, Russia \\ 1Nabdikeev@fa.ru,2OVLoseva@fa.ru, ${ }^{3}$ mvmelnichuk@fa.ru
}

\begin{abstract}
The transition of the Russian economy to a path of innovative development and deployment of new technologies and intellectual tools means, in particular, a change in the system of factors of economic growth and their role. Under these conditions, intelligence and knowledge, new technologies, organizational potential and human resources become the major driver. As a result, during the transition of the economy to the sixth technological order, issues of development trends and improvement of intellectual capital become highly relevant. The paper discusses conceptual approaches to the principles of intellectual capital (IC) management, proposes innovative management strategies, analyzes problems that complicate the process of managing intellectual assets, and provides methodological recommendations for obtaining operational analytical information on the effectiveness of the processes of creating and using intellectual capital.

Keywords: intellectual capital, intellectual capital management, digitalization of society, sixth technological order.
\end{abstract}

\section{INTRODUCTION}

The transition of the economy to the sixth technological order places new requirements on managing socio-economic entities (employee, organization, region) and demands from the top brass above all things the efficiency in managing the human intellectual activity since it is the latter that creates intellectual capital that provides increasing income and additional competitive advantages in the fight for technological leadership [16; 14].

In this regard, the search for new approaches to the formation and evaluation of the human capital, the development of its structure based on the human intellectual competences and meeting the realities of a new type of economy is a relevant issue. This approach can be referred to as human-oriented, and its characteristics are largely determined by the qualitative features of the sixth technological order related to the human capital.

First, there is a significant advance in the pace and scale of informatization and digitalization of society compared with the rate of change of human resource competencies.

From this follows the second feature of the new order - the need for continuous training and retraining of workers throughout their lives. The structure of the individual's intellectual capital should allow the employee to acquire new knowledge at any age and ensure that his intellectual potential is unleashed most effectively. It means that by and large, the structure of the intellectual capital of an organization should be also based on constituent elements of the human intelligence.

The third feature of the sixth order based on innovation, large amounts of digital data and knowledge bases, is the growth of the knowledge-intensive production and the market of intelligent products and services, which leads to the dominance of workers engaged in innovative manufacturing, transfer and use of new information and knowledge. Under these circumstances, the creative component of intelligence that ensures the effectiveness of innovative activities is coming to the forefront. The fourth feature of the new economic order is associated with increased cross-country competition in high-tech industries characterized by faster replacement of goods and services and reduction in the life cycle of innovations. 
The main factor in ensuring competitiveness is the effective management of intellectual, particularly human, capital, which requires the development of appropriate models and methodological tools for its formation and evaluation.

The identified specific features of the sixth technological order related to the human capital necessitated the expansion of its interpretation taking into account its interrelationship with intellectual capital (IC) along with the development of an appropriate human capital structure, models and tools for its formation and evaluation.

The scientific and theoretical basis to ensure that the above needs are duly met is the concept of human capital management designed to link the new technological order with the formation of a new type worker and economic development trends [6], [13].

The implementation of the human capital management concept under the sixth technological order requires that the interpretation of human capital is expanded by entering new components into its content and structure.

Historically, researchers identify three main components of the human capital [5].

- $\quad$ vital (capital of health);

- labor (capital of professional activity);

- intellectual (capital of knowledge, skills inseparable from the individual).

Therefore, in the context of the sixth technological order, the intellectual component of the human capital is beginning to play the leading part. It is advisable to expand the interpretation of the employee's intellectual capital to include not only inalienable knowledge and skills but also products of his intellectual activity (IA): formalized knowledge and useful information applicable in the organization (alienated capital). Consequently, the human intellectual capital (human IC) including the components of human and intellectual capitals in their traditional interpretations can be regarded as an independent type of capital.

The vital capital of employees is excluded from the corporate human intellectual capital but the professional and personal capital is included in the form of qualification characteristics. The other part of the professional and personal capital (moral and cultural values, worldview) is not considered in the context of the intellectual activity predominant at the stage of the sixth technological order and, accordingly, not evaluated.

An important issue is the development of IC management methods and models [10; 3; 7].

The IC management process is understood as a set of actions and activities aimed at ensuring efficient planning, organization and control of the processes of formation, development and use of the corporate intellectual assets along with the motivation of the processes of accumulation and multiplication of intellectual assets. In this regard, the goal of IC management in the organization is to achieve the maximum result in the IC utilization with the minimization of its development costs $[8 ; 9 ; 11]$.

\section{IC MANAGEMENT TASKS}

The analysis of specialized domestic and foreign literature on the subject under consideration makes it possible to formulate the IC management tasks that include the following [2]:

- planning, organization, control and regulation of the processes of creation and development of intellectual assets;

- creating an atmosphere of openness to innovation, ensuring the development of employees and their motivation for the accumulation and multiplication of the IC;

- development of the organizational and methodological base for the IC management and the conditions for its effective use;

- organization, control and regulation of the process of information flow circulation inside the enterprise;

- organization, control and regulation of the process of information flow circulation between the organization and the outside environment; 
- planning, organization and control of the process of making a portfolio of rights to intellectual property objects (IPO) as a tool for regulating product markets;

- planning, organization, control and regulation of the processes of using intellectual assets in the external and internal environment of the organization.

The management tasks posed should be solved within the framework of specialized IC management systems.

The analysis of specialized domestic and foreign literature on the subject under consideration makes it possible to formulate the IC management tasks that include the following [2]:

- planning, organization, control and regulation of the processes of creation and development of intellectual assets;

- creating an atmosphere of openness to innovation, ensuring the development of employees and their motivation for the accumulation and multiplication of the IC;

- development of the organizational and methodological base for the IC management and the conditions for its effective use;

- organization, control and regulation of the process of information flow circulation inside the enterprise;

- organization, control and regulation of the process of information flow circulation between the organization and the outside environment;

- planning, organization and control of the process of making a portfolio of rights to intellectual property objects (IPO) as a tool for regulating product markets;

- planning, organization, control and regulation of the processes of using intellectual assets in the external and internal environment of the organization.

The management tasks posed should be solved within the framework of specialized IC management systems.

\section{IC MANAGEMENT PRINCIPLES}

Taking into account the above-listed management tasks and the special informational and intellectual nature of the IC, the following principles of the IC management can be formulated:

1. The results-oriented principle. Since the IC management includes a variety of creative processes difficult for organization and control, the planning of employees' operations is based on the goal to be achieved or the result rather than the task. Compliance with this principle implies that an employee or a working group is committed to complete all stages of the process making it possible to create an atmosphere of creative work and increase the possibility of a successful completion of the work.

2. The results-dependence principle. When specialists are interested in the result they can perform all stages of the process individually using expert systems and databases. In this case, the need for monitoring of operations is reduced, which makes the control function a prerogative of the top management.

3. The principle of a single fixation of information at the source. With modern information technologies, information is entered into databases accessible to all interested users. Given the special information nature of the IC, it becomes possible to restrict the access to certain databases and use data protection tools. Relational databases and data exchange systems make it easy to enter, collect, store and transmit information. Through a single data entry by an information source and the system integration, an enterprise is able to eliminate redundant data entry, increase its reliability and avoid the need to correct inevitably occurring errors.

4. The principle of information processing by its generator. Given the fact that the IC management is largely the management of information flows, a necessity arises to reduce linear links and perform optimization. In this regard, it seems advisable to include information processing into the real process that generates this information. This will 
reduce the time of information processing and the number of errors that occur during its processing.

5. The principle of coordinating the process leading to the overall result. A characteristic feature of the IC management is the parallel processing of information. Different working groups perform the same function or different groups perform different functions leading to a common result. The simultaneous execution of various stages of work saves time but inconsistencies often arise in the integration and testing phase. Observing the principle of coordinating the process leading to the overall result creates links between parallel functions and allows coordination of respective actions in the process of their implementation rather than at the end of the work stages.

6. The principle of decentralization in decision making. The specific nature of knowledge-based activities necessitates a high degree of responsibility of employees for their decisions. Modern information technologies make it possible to record and process data, and expert systems are to some extent able to provide the knowledge needed by employees to make independent decisions. The number of the management hierarchy levels thereby can be reduced, and the organization itself can be made more compact. In this regard, the role of the leader is changing: from a supervisor and a boss, he turns into a help-mate and counselor.

7. The principle of the control-embedded the process. As already noted, the process of creative activity is quite complicated in terms of its control. Compliance with the principle of embedding control into the process allows employees to independently control intermediate results.

\section{IC MANAGEMENT STRATEGIES}

There are 10 strategies for managing intellectual capital with a view to create company value:

1. The exchange of knowledge between employees (within human capital).

2. The increase in consumer capital.

3. The circulation of intangible assets within consumer capital.

4. The transformation of employee knowledge into consumer capital.

5. Workforce training through practices used in the consumer capital.

6. Embedding human competencies in the internal structure of the company.

7. Employee training using organizational capital resources.

8. Management of information flows from organizational capital to consumer capital.

9. Management of information flows from consumer capital to organizational capital.

10. Management of all above-mentioned types of movements of intellectual capital

\section{FACTORS COMPLICATING THE IC MANAGEMENT PROCESS}

The special nature of products created and manufactured at the research-intensive enterprise causes the following problems that complicate the management of intellectual assets:

1. The need for significant investment in IC creating, ensuring exclusive rights and $\backslash$ implementing measures to prevent unfair competition.

2. The need to train highly skilled specialists for research, production and management.

3. The need for informatization of business processes including creation of branched databases allowing to control the process of IC managing.

4. The difficulty in determining the duration of the life cycle of IC elements.

5. The multiplicity of IC elements and complexity of their identification.

6. The difficulty in determining the market value of specific intellectual asset (IA), as well as determining its contribution to the value of the final product.

7. A high degree of risk in making managerial decisions in IC management because this area is characterized by a high degree of uncertainty.

8. The need to coordinate many different IC management functions. 
9. The rapid growth of business space protected by patents and the complexity of tracking the process that could result in violation of the rights of competitors and the emergence of additional costs.

10. The dynamism of innovative processes and rapid updating of all types of IC organizations makes it necessary to constantly introduce corrections in the organizational support of IC management process.

11. A long time for patenting of industrial property.

12. Imperfection of the theoretical and methodological framework.

\section{EVALUATION OF THE MANAGEMENT EFFECTIVENESS}

OF IC ORGANIZATION

The output of the IC management system development is data on the effectiveness of the IC management system functioning since these data reflect the result of the development and implementation of the mechanism for organizational support of the IC management process as well as serve as criteria for judging the effectiveness of the in-house IC management system. To obtain this kind of information, it is obviously required to use the appropriate methodological framework allowing to assess the effectiveness of the intellectual asset management system functioning and evaluate the effectiveness of the processes of creating and using of such assets while making managerial decisions $[1 ; 4 ; 12]$.

Modern Russian enterprises conduct only accounting of intangible assets while valuation of efficient use of such assets remains outside the scope of managerial activities. The current situation is caused by a number of factors, above all, by the imperfection or complete absence of methods for assessing the effectiveness of IC management system as well as the effectiveness of IC generation, use and growth.

The implementation of suggested recommendations would help in solving the following problems:

- improving information and analytical support for IC management processes;

- enhancing the foundation and quality of management decisions;

- reducing the degree of uncertainty and risk in operations with IC;

- providing rational redistribution of information and intellectual resources.

Moreover, these indicators can be used as guidelines in the development of an enterprise strategy for generation, acquisition and use of IC.

It should be noted that assessment of the effectiveness of IC management system implies calculation of the set of indicators. This is due to the fact that the IC management process itself involves the implementation of a huge number of functions which are quite difficult to evaluate in terms of quality. Thus, the assessment of effectiveness of the IC management system is a complex procedure that is similar to the estimation of the financial state of an enterprise.

Methodological recommendations on the assessment of effectiveness of the IC management system as well as IC generation and use include the implementation of the following steps:

1. Calculation of statics indicators (i.e. indicators needed to assess the IC management system arrangement).

The set of statics indicators includes indicators of the functional and structural arrangement of the IC management system, i.e. the level of its functional and structural order.

The level of IC management system arrangement would reflect its ability to adapt at minimal cost to the external environment changes through the use of its structural and functional capabilities. An increased level of IC management arrangement is identified with an enhancement of the IC management system as a whole.

The arrangement of IC management system should initially provide the maximum approximation of its functional and structural order to a rational value. The achievement of a rational value implies that in the existing IC management system all the functions, elements and communications 
are useful, and the number of coordination functions and intermediary elements performing the coordination functions is minimized.

It can be assumed that the level of IC management system arrangement can be assessed by analogy with one of the production system because the IC management system is similarly characterized by the set of elements and links between them.

2. Calculation of dynamics indicators (i.e. quality control of executing functions by IC management subsystems) for the current date.

At this step, the dynamics indicators are calculated. They allow to evaluate the dynamics of executing of basic functions involved in generation and use of intellectual assets (IA) by the following IA management subsystems:

- a subsystem for managing R\&D and technological innovations;

- a subsystem for managing external information and communications;

- a subsystem for managing internal information and communications;

- a subsystem for managing innovative potential and workforce development;

- a subsystem for managing organizational and methodological base;

- a subsystem for managing a portfolio of rights to intellectual property;

- a subsystem for managing the commercialization of IA and valuation activities.

3. Comparison of the results of calculation of dynamics indicators for the current (present) and base (past) date.

At this step, the dynamics indicators calculated for the base and current date are compared. The dynamics of indicators and the deviation (in percent) from indicators calculated for the base date are determined.

4. Comparison of the values of calculated indicators with the "reference" values of similar indicators.

When conducting an economic analysis, the reporting level of the calculated indicators should be compared with actual levels for other periods of time. However, the nature of the dynamics of these indicators alone cannot testify the acceptability of the achieved value of indicators. It is necessary to develop a basis for comparison. For this purpose it is possible to use such indicators as the level of similar indicators of competitors or the best indicators for developed countries as well as reference and normative levels of indicators (the latter is determined by expert-statistical method and it is the most acceptable in management practice).

Only by setting the normative levels of dynamics indicators and comparing them with the actually achieved levels, it is possible to identify reserves for improving the use of products of intellectual activities as a part of the assets of an enterprise as well as to develop and implement measures to mobilize existing reserves.

5. Calculation of output indicators.

Output indicators characterize the level of return on the use of IA as resources or end products.

6. Identification of problem areas in functioning of the IC management system and arrangement of the processes of IC generation and use.

The results of calculation of output indicators along with comparison of dynamics indicators with the base and reference ones would allow to identify deviations that can be evaluated negatively. In this regard, it is necessary to answer the question why such deviations occur. Since dynamics indicators are structured according to IC management subsystems, the process of identifying problem areas is greatly simplified.

7. The development of recommendations for eliminating problem areas in functioning of the IC management system and in the arrangement of processes for IC generation and use.

At this step, proposals to correct the current situation are formulated and areas contributing to the increase in efficiency of the IC management system and refining of the processes of IA generation and use are determined.

8. Issuance of the analytical report on the results of evaluation of the effectiveness of the IC management system and processes for the IC generation and use. 
The results of the last two steps should be systematized and presented in the form of a report giving operational analytical information on the status of IC management; the report should be used to create plans for further development of the IC management system.

The application of the developed methodological recommendations to evaluate the effectiveness of the IC system creation and use would enhance methodological support for the IC management process and significantly increase the profitability of intellectual activities.

The work was carried out under Russian Foundation for Basic Research grant № 19-010-00698 on the theme: "Development of the theory of intellectual capital and methods of its evaluation in the context of digitalization of the economy".

\section{REFERENCES}

[1]. Abdikeev N. M., Brezhneva T. V. Methods of assessing the intellectual capital of the company, in Innovative technologies of cognitive management in Economics, management and education. M.: REA named after G. V. Plekhanov, 2008, pp. 93-99.

[2]. Abdikeev N. M., Kiselev A. D. Knowledge Management of Corporation and Reengineering of Business. Moscow: INFRA-M, 2011.

[3]. Abdikeev N. M. Managing intellectual capital of the organization," in Innovative development of Russia: problems and solutions, eds. M.A. Eskindarov, S.N. Silvestrov. M.: ANKIL, 2014, pp. 603-634.

[4]. Abdikeev N. M. System of evaluation of intellectual capital and intangible assets created on the basis of intellectual property, in TEDS'18. Proceedings of the International Conference on Technology Entrepreneurship in Digital Society, 2019, pp. 135-140.

[5]. Dyatlov S. A. Fundamentals of the theory of human capital. St Petersburg: Publishing house of St. Petersburg University of Economics and Finance, 1994.

[6]. Donkin R. Human Capital Management: A management report. London: Croner, 2005.

[7]. Fedotova M. A., Dresvyannikov V. A., Loseva O. V. et al. Intellectual Capital of the Organization: management and evaluation. Moscow: Financial University under the Government of the Russian Federation, 2014.

[8]. Firer S., Williams M. Intellectual capital and traditional measures of corporate performance, Journal of Intellectual Capital, 2003, vol. 4, no. 3, pp. 348-360.

[9]. Gogan L. M., Duran D.C. Intellectual capital management - a new model Practical, Application of Science, 2014, no. 2 (6), pp. 57-64.

[10]. Jelcic K. Intellectual capital: Handbook of intellectual capital management in companies. Croatia: Intellectual Capital Center, 2007.

[11]. Kianto A., Andreeva T., Pavlov Y. The impact of intellectual capital management on company competitiveness and financial performance, Knowledge Management Research \& Practice, 2013, no. 11 (2), pp. 112-122.

[12]. Loseva O., Fedotova M., N. Filimonova, Methods for Measuring of Regional Intellectual Capital, Information, 2016, vol. 19, no. 6, pp. 1771-1784.

[13]. Marr B., Schiuma G. Measuring and managing intellectual capital and knowledge assets in new economy organizations, in Handbook of Performance Measurement, ed. M. Bourne. London: GEE Publishing, 2001.

[14]. Senyucel Z. Study guide: Managing the human resource in the 21st century. London: Ventus Publishing, 2009.

[15]. Intan S. M., Rahman S.A., Abbas M. Intellectual capital and its major components, Journal of Technology and Operations Management, 2015, no. 10 (1), pp. 15-21.

[16]. Sharkova A. V., Abdikeev N. M., Bogachev Yu. S. et al. Substantiation of approaches to development of model of competitiveness of social and economic systems in the conditions of digital economy, Problems of economy and legal practice, 2019, no. 1, pp. 23-28. 